\title{
Making the Social Hold: Towards an Actor-Network Theory of Design
}

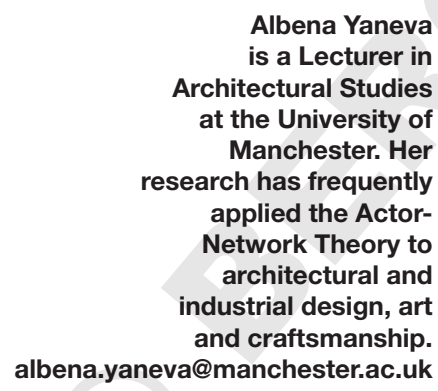

Albena Yaneva at the University of Mer applied the ActorNetwork Theory to architectural and arial design, art albena.yaneva@manchester.ac.uk

\section{Albena Yaneva}

ABSTRACT The article illustrates the potentials of an Actor-Network Theory (ANT) perspective to design. Drawing on ANT's assumption that objects with their scripts and incorporated programs of action compel and rearticulate new social ties, I argue that design triggers specific ways of enacting the social. It is impossible to understand how a society works without appreciating how design shapes, conditions, facilitates and makes possible everyday sociality. Viewed as a type of connector, not as a separate cold domain of material relations, design's investigation might shed light on other types of non-social ties that are brought 
together to make the social durable. The article also discusses some steps towards an ANT of design and suggests a new research program for design studies.

KEYWORDS: design, Actor-Network Theory, society, social ties, script, Bruno Latour

\section{A Morning Trajectory: Handrails, Stairs and Elevator Buttons}

In a hurry for my lectures I enter the university building. As usual, I am immediately confronted with a choice between the staircase or the elevator. Either will guide me to my office. At this particular moment, as I rush and worry about arriving moments after the lecture theater is filled with students, the staircase and the elevator offer two ways of reaching the auditorium at two different speeds. As I decide between them, I will not simply choose between mobility and immobility, activity and laziness, exercised control and self-control; rather, I will be led to share agency with them in a different way.

Equipped with different socio-technical devices that mediate our actions, the staircase holds a "vision of the world" inscribed in its construction, a specific script: ${ }^{1}$ the width of the stairs, the inclination of the staircase, the affordance ${ }^{2}$ of the handrail, all these

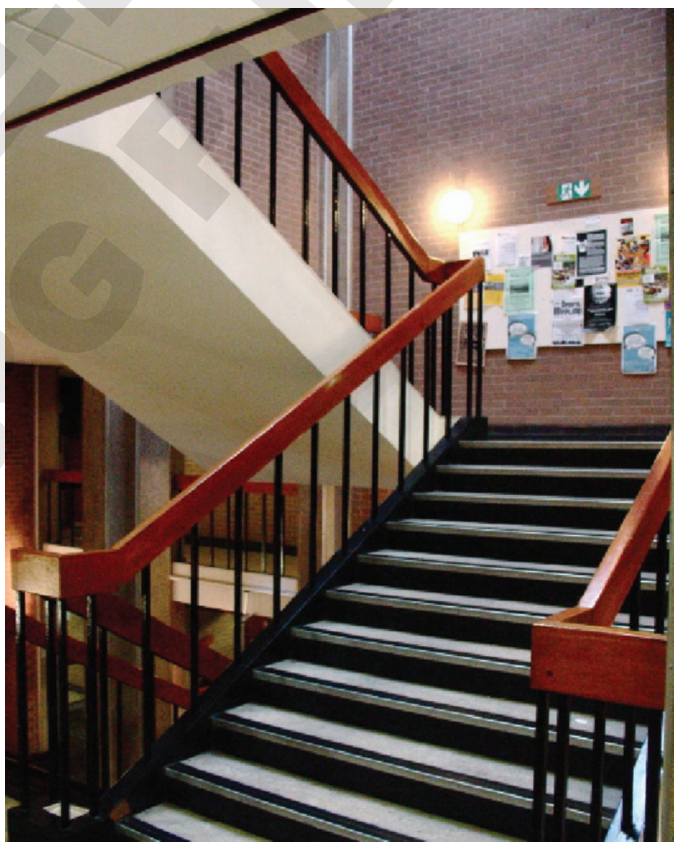

Figure 1

The staircase in the Kantorowitch building, the University of Manchester. Photograph by Albena Yaneva. 
features of their design are important for me as I climb the staircase. The different qualities of the handrail afford particular actions. In its smoothness and warmth, the rail's wooden surface contributes to the easier gripping actions of my hand as I go up. Its wide and inviting surface makes me lean upon it in conversation with colleagues during an on-stair encounter. The narrow stairs make it impossible to ignore others whom I might meet occasionally. The stairs' design triggers spontaneous face-to-face conversations, making us extend the auditorium discussions in other university spaces. They pre-dispose my body to delegate part of the action to the setting; I feel comfortable when going down the stairs (and not so comfortable when climbing back up them). Not only is the staircase animated by the chaotic intervention of unpredictable walking users, crossing each other, interacting and sharing the space, but it is also filled with noises and smells coming from the cafeteria. I walk and encounter fellow colleagues and students in the building. Meeting and chatting on the staircases, I find myself involved in relationships mediated $^{3}$ by the particular design of the building, the staircase and the numerous artifacts that facilitate my morning trajectory, making my arrival pleasurable.

At the same time, bodies in the elevator are not passively waiting to be transported. When I push the button, I do not delegate the whole action to the elevator, waiting patiently to be transported from the ground to the second or the third floor, to the auditorium or to my

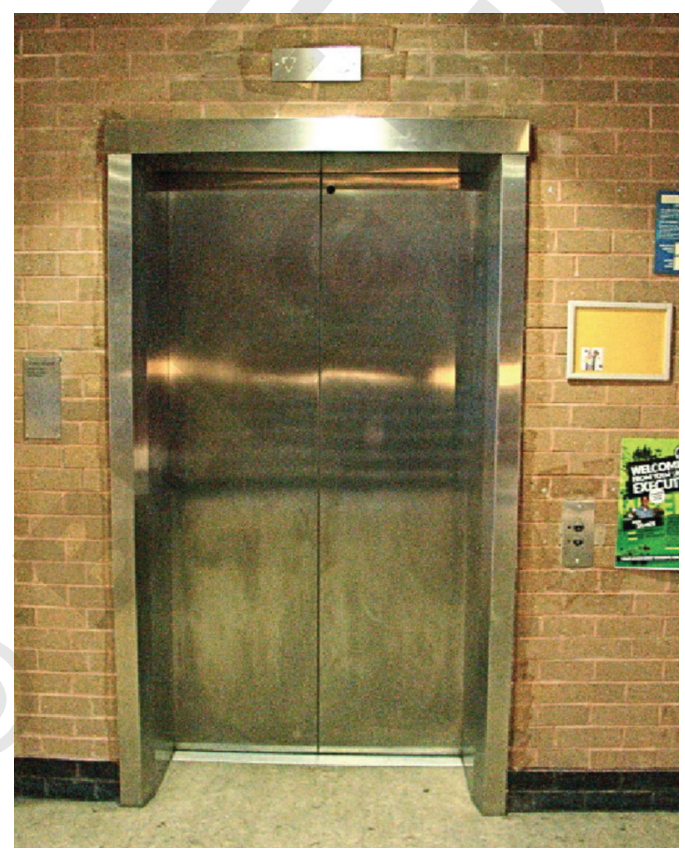

Figure 2

The elevator. Photograph by Albena Yaneva. 
office. I delegate 4 part of my action to the floor indicator, and I remain in a state of ambivalent tension, of anxious activity of doing nothing, frightened by the possibility of an accident, or bothered by the presence of other people. Embraced by the setting, our actions are finely mediated by technical devices: the elevator buttons, the floor indicator and the alarm system all emphasize the social dimension of being together (Hirschauer 2005). If we communicate in a different way in the elevator and on the staircase it is because they offer two different modes of distributing agency with the environment. Designers have chosen between two ways of delegating action to the nonhumans: ${ }^{5}$ elevators and staircase, corridors and rooms, handrail and keys, walls and doors - of two ways of reassembling the social. ${ }^{6}$

If the morning trajectory of many university lecturers like myself is pleasurable, it is because many objects afford and facilitate our activities, obliging us to do certain things and forbidding us from doing others. By so doing, they make me reach my students in time, and more often in a good mood. Designers have worked hard to produce a world of objects and environments that aim at assisting and pleasing users like myself; it is, I will argue here, a specific social contentment that grows bigger when we collectively share the enjoyment of using objects or inhabiting purpose-built environments together. The pleasure is of a shared taste, a judgment or appreciation that gets stronger when it is being reappraised and repeated by many users like myself. That is, design is not merely a beautiful aesthetic envelope that covers objects and makes my university mornings pleasurable. Instead, design has a social goal and mobilizes social means to achieve it, thus striving to enrich not to diminish, to fortify not to weaken the public bonds.

Let me pause for a moment and look back at the artifacts that guided me in my morning trajectory. Attempting to describe this routine trajectory, I looked at the university's material environment, describing mundane artifacts in a pragmatic manner. I avoided an analytical frame of mind. This view allowed me to witness what objects do and to understand their pragmatic meaning. That is how I have chosen to illustrate what an Actor-Network Theory (ANT) perspective could bring to design. The ANT approach does not limit its analysis to the structure of objects. Drawing on the ways technical objects take part in the making of culture, that is, the anthropology of technology, ANT shows how every single technical feature of an object accounts for a social, psychological and economical world. Moreover, within these worlds, each is supposed to work and evolve, redefining the contours of the technical object. Such a socio-technical analysis of objects (Akrich 1991) cuts across the dichotomy of subjective-objective, exploring the simultaneous genesis of objects and their environments (Akrich 1989).

Although ANT scholars do not refer explicitly to the notion of design, in their writings they analyze extensively the coming into 
being of different objects, the way they work and how they are capacitated to act; their findings are predominantly based on accounts of such technical objects as seat belts, door hinges and key systems. Assuming that the structure of the material world pushes back on people, ANT argues that artifacts are deliberately designed to shape or even replace human action. They can mold the decisions we make, influence the effects of our actions and change the way we move through the world. By so doing, they play an important role in mediating human relationships, even prescribing morality, ethics and politics (Latour 1991).

In his revision of the ecological approach of James J. Gibson (Gibson 1979), another source of inspiration for ANT, Donald Norman warned us not to confuse affordance with perceived affordance, or affordances with conventions as affordances: "Designers can invent new real and perceived affordances, but they cannot so readily change established social conventions" (Norman 1999: 38; my emphases). Yet, ANT provides a more optimistic theoretical offer, explaining how design can help us shape the social differently. It suggests a new research program for design studies (which I will discuss in the third section of this essay). This is an illustration of how the pragmatic meaning of a design artifact, a door lock, is to be treated in an ANT-inspired perspective. It examines how objects with their scripts and incorporated programs of action compel and rearticulate new social ties, how the way they are shaped and designed is related to specific ways of enacting the social.

\section{Doors, Locks, Key Systems and Auditoriums}

Once on the first floor, a code is supposed to make me open the resource room (while my key, a key always lost somewhere in between lecture copies and books while I hurry to the lecture theater, helps me access my personal office). And here I am, face to face with the special mechanical-code door lock.

One button on the right, then two subsequent buttons on the left and then ... one more on the right ... two more on the left. I do not remember the code anymore; my hand recalls and hectically reproduces a movement that it has memorized through numerous repetitions, but that my fragile lazy morning brain can hardly recall ... I make my hand repeat it, and here I am in the resource room. This fully mechanical pushbutton operation is quite different than the one my hand has to perform in the morning to set up the house alarm when going out for work. This security method holds several advantages when compared to the standard individual key that opens my personal office: no need to take an extra key with me to open the resource room, no need to lock the door when you go out (it locks by itself when closed), several seconds are enough to change the code where a lost key might force you to remove the lock. This mechanical, keyless coded door lock system allows my colleagues from our research center to access the resource room,

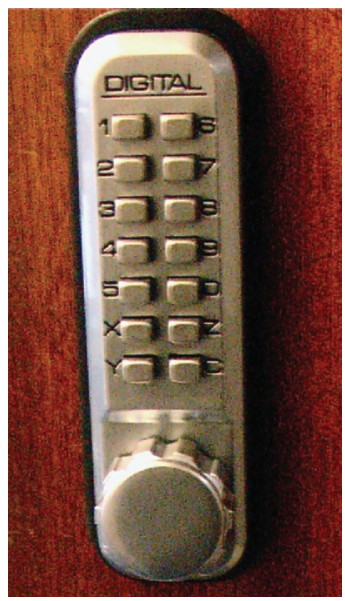

Figure 3

The mechanical-code door lock of the resource room. Photograph by Albena Yaneva. 
obliges us to close the door behind (as the door is very heavy) so as to impede random visitors to the building who might use university resources, and prevents colleagues from other research units from gaining access to the room (they cannot dial the same combination of buttons when attempting to access the room).

A simple keyless door lock tells us a lot about the social life of the university. An ANT view of this artifact requires us to take Latour's suggestion seriously: "We should not state that "when faced with an object, ignore its content and look for the social aspects surrounding it'. Rather, one should say that 'when faced with an object, attend first to the associations out of which it's made and only later look at how it has renewed the repertoire of social ties'" (Latour: 2005: 233). ${ }^{7}$ The implications of the particular design of the lock cannot be conferred on the symbolic relationships between departments, disciplines, hierarchies, divisions of labor, the university building design or the psychological need of university fellows to double the number of locking mechanisms and key devices that would guide them to their mail boxes and copy machines. An ANT approach does not try to unveil "the hidden meaning" of a design; the making of this lock implies a particular way of regulating and maintaining the social. Made so as to allow only colleague fellows to access the research group resources and to impede others from using them, this simple mechanical door lock divides and congregates university fellows in a particular way. Thus, it mediates the social relations between researchers, students, random visitors and colleagues from the other departments. Rather than being an intermediary that would "express," "reify," "objectify" or "reflect" university policies, the institutional order and rules (thus serving as a mirror of institutional life), the lock acts as a mediator that constitutes, recreates and modifies social relationships. By authorizing only my colleagues to enter the resource room and by sending away those that are unable to perform the specific pushbutton operation, the lock regroups university users and reconnects them differently. That is, design functions socially; the social is not outside it, at a cosmic distance from its objects. It is in the objects' world. Design allows this door lock to take on the conflicting wishes and needs of many university colleagues. "It transcribes and displaces the contradictory interests of people and things" (Latour 1991: 153; emphasis added). By using and misusing locks and keys, ${ }^{8}$ doors and corridors (Evans 1997), we deal with social relations continued by other means wood, steel, glass, metal buttons (Latour 1996) - and amplified by their design.

The design of the auditorium where my morning trajectory ends also has an impact on the way I lecture and on the particular forms of socialities established with students and colleagues. It creates a cognitive environment adjusted to the task of education. What follows is an analysis of the possible grammar of actions this design can have, rather than of its symbolic language. 
If I were to teach in a circle-shaped room, the latter would afford an unobstructed view, allowing the students to be seated in a circle at an equal distance from me as a lecturer; this solution also allows all eyes to be fixed on me as a speaker, while also permitting them to see their colleagues. Allowing students to see and to be seen by others, it also enables a form of equality. The circular arrangement of space facilitates a specific type of university communication. It relies on the transparent immediacy of sights, forming a collective mutual gaze. A circular arrangement of the lecture room would mean that students' opinions or questions could appear from all angles. Nevertheless, this type of lecture room has often manifested a persistent problem of diffusion of sounds and speech. Bad acoustics would require the lecturer to raise her voice and to engage in a more "violent" type of communication.

Alternately, a semicircular auditorium would imply a different material arrangement, while also providing a disparate cognitive environment for teaching and learning. Being placed at the center, the lecturer would draw all eyes toward her, capturing everybody's attention; she can be easily seen and heard. This arrangement of the room offers students, wherever they may sit in the semicircle, a view of the lecturer and the screen next to her. The space in such a room would be focalized by a kind of "column of speech" constituted by the lecturer on her podium and the distance between the speaker on the podium and the listeners will be architecturally regulated.

The two types of material arrangements of the auditorium would condition two different types of cognitive design, two distinctive ways of students-lecturer communication, and would correspond to two different educational philosophies: the circular arrangement would favor mainly visual communication, whereas the semicircular one would rely on speech. The cognitive environment of the auditoriums would also make possible the creation of different types of associations between lecturers, students, teaching objects and program administrators and would shape, format and facilitate different types of activities. Thus, just as the script of the conference room creates a specific environment, impacting the way I lecture and communicate with students, ${ }^{9}$ the door lock of the resource room alternately creates an environment of privacy and isolation, on one side, and a place for communication with other fellows from the same research group, on the other; this double requirement for isolation and communication better suits the task of research. Design offers us a mechanism for arranging and invigorating the university world.

By releasing the coded door in the same way as our colleagues, we know we share the same research unit and the same little pleasure of making a design artifact work successfully. This little morning ritual inspires self-confidence - I am here and if the door opens that is because I belong to this group, to this institution; I share something with others, I take part in this institutional rhythm. Its design can fill 
me with a sense of enjoyment. It is another attachment to my work that makes my morning trajectories to the auditorium fun and my university work pleasurable. If I feel relieved when the door finally opens and my hand successfully accomplishes the movement that it learned years ago, I know that I not only share with others the same university ID card, but also share a series of worries. Might I forget the code? Or make an unfortunate hand move? Will I find the door open and irresponsibly unattended? There is also the relief of being able to finally open it. I am pleased, and I know this contentment is shared by other colleagues today; that is, we share something more than the university policy or the institutional rules. We share the possibility of being connected with specially designed doors and locks. We are connected by design, and that is a social enjoyment.

\section{Some Steps Toward an ANT of Design}

We cannot understand how a society works without appreciating how design shapes, conditions, facilitates and makes possible everyday sociality. If you follow me for a moment, again, in my trajectory, you will witness how the objects from my university mornings (my key, the door lock of the resource room, the elevator buttons, the staircase handle, the conference room arrangement) do not stand for social forces and divisions, nor do they symbolically represent the university's order, hierarchy or divisions of labor; rather, they perform the social as we use them, and connect us in a new way with fellow colleagues, students and university administrators. We remain linked by using the same objects, by facing the same functional problems, by committing the same ergonomic mistakes. We open ourselves to subjective fragility when the door code is forgotten, just as we enjoy the ways objects function once amplified by a better design. With its networks made of different heterogeneous materials, design guides me in the university spaces, affords my movements, diminishes my insecurities and fears, strengthens my authority in the lecture room and harmonizes my social collaboration with other academic colleagues. Design stands here for what makes the social diversity of a university world hold together, as a way to produce, adjust and re-enact the social.

I do not suggest that the "social" is a separate field or even a context in which design could be framed. Rather, "the social" is glued together by many other types of connectors (Latour 2005), including design. As a type of connector, design is not a separate cold domain of material relations. Viewed in this way, its investigation might shed light on other types of non-social ties that are brought together to make the social durable. Expanding the project of ANT to the field of design requires mobilizing this method's persistent ambition to account and understand (not to replace) the objects of design, its institutions and different cultures. This means we must understand the designerliness of design objects, networks and artifacts, instead of trying to provide, by all means, a stand-in 
(social, psychological, historical or other) explanation of design, i.e. a psychological explanation of the creative energies of the inventor, a psychoanalytical explanation of the client-designer-user relationship, a historical explanation of the social contexts of design.

Design connects in very specific ways. Whenever designers work on a project, stage a presentation for a client or present a mock-up, or when we, as users, use and misuse artifacts or find ourselves entangled with the environments and networks of design, we deal with an attachment that is typically the nature of design. What does it mean for a public to have an opinion about a particular design project or trend? What does it mean for a scale model/prototype to be created via the repetitive processes of scaling up and scaling down that designers are constantly undertaking? What does it mean for a user to disagree with a design solution? Such issues are to be treated with extreme care, instead of quickly explaining them as the result of social factors or elucidating the solidity of design ties by appealing to the extraneous force of society. The ties created with design are unique. They do not look like regular "social ties." Indeed, we are all linked by very specific and fragile design ties: I redesign and rearrange the conference room for my students; the university buildings and its circulation system have been carefully designed for me, other academics and also our students; on a daily basis I use and misuse the staircases and elevators, I struggle with doors, coffee machines and a special door lock designed for me. Glass walls allow me to see and interact more with my fellow colleagues; I vote for the architectural project "X" soon to be constructed as a new building on the campus. These ties do not bind us socially; they bind us by design. In that sense, "design" is also a mode of connection that cannot be explained by other economical, social, political means. It has its own way of spreading, its own objectivity, its own solidity. Together with legal, technical, artistic and religious ties, design helps make the social durable.

Imagine how many users like myself are about to perform the same ritual of entering the Kantorowitch building this morning, choosing between staircase and elevator, forgetting their code in front of the resource room and struggling with the door before they finally enter the lecture room. To learn to be a good user, I watch the others to see how they use these objects, devices and environments, how they share the elevator, and struggle with the door code. These are all social acts; without the example of other users of the building whose mistakes we involuntarily tend to repeat, we would not be able to act socially. Impatient to reach the second floor I push the button of the elevator; like many colleagues I dial the code in the resource room and follow the gestures of other fellows at the copy machine. That is how design makes it possible for many imitative and repetitive acts to proliferate and generate new social connections. The imitative repetition ${ }^{10}$ of all those morning rituals by many of my colleagues is eminently social, as it groups and regroups 
us according to the types of objects and environments we inhabit and enact, and makes us feel part of the same institution. Some of these ways of acting, which are also ways of thinking afforded by design, acquire, as a result of repetition, a sort of consistency and reliability that precipitates them, so to speak, and isolates them from the particular events in which they are embodied.

Design makes us gain access to the social, but it is a molecularized social, discovered in individual objects, users, designers and inventors. If many individual users like myself do not repeat what design has implied, nothing remains of the social. Design ensures that we encounter numerous nonhumans (objects and environments) in our routine trajectories, and mediates our communication with other humans. It makes possible the university order, academic collaboration, collegiality and educational philosophy. This order is passed on, not from the social institution (or social group) collectively to the individual, but rather from one individual to another individual, from one colleague fellow to another one, from student to lecturer, and, in the passage of one human into another human, it is refracted. The sum of these associations, from the initial impulse of an inventor, a discoverer, an innovator or modifier, whoever it might be, unknown or illustrious, is the entire reality of the social.

Thus, design is not just a way to render objects exotic, desirable or pleasurable. It is not a simple superstructure, an epiphenomenon; nor is it a separate system or domain that may be explained only through the study of external contexts, societies, markets, developments in technology or individual genius. Design, I argue, is a way of producing additional attachments that make a variety of actors congregate, forming different groupings and assembling social diversity. Tracing networks with wood, steel, polished surfaces and blinking signals, bip-ping doors and blinking elevator buttons, design connects us differently, linking disparate heterogeneous elements and effects, thus entering a game of producing, adjusting and enacting the social.

To tackle design as a type of connector, as a mechanism for energizing and setting the world in motion, we should not limit our analysis to the discourses of designers and inventors. Tackling their stories of invention falsely separates the aesthetic and the technical, form and function, styling and engineering. It prevents us from embracing the diversity of the creative process. An ANT approach to design would consist in investigating the culture and the practices of designers rather than their theories and their ideologies, i.e. to follow what designers and users do in their daily and routine actions. This occurs in spite of their interests and theories. Thus, the pragmatic content of actions, not of discourses, is constantly prioritized, distinguishing between "design in the making" and "design made." Yet, such an approach does not consist in the simple description of design practices or routines, nor is it enough to discuss and analyze relevant design theories. Instead, we should study the experiences 
of both users and designers, as well as the numerous connections that this research would reveal.

We should be able to capture the movements of artifacts and designers in the design studio. We can, for instance, follow their routine practices and account for their actions and transactions in complex spatial settings. In so doing, we would study not only the materialization of successive operations, performed on a daily basis, but also the foreseen and unforeseen effects they might trigger. This application of ANT has appeared in numerous fields: technology, music, medicine, engineering and architectural design. ${ }^{11}$ By following what both designers and users do, how they engage with objects and technologies, how they seize, handle and evaluate them, how they attribute meaning to their actions, form different groupings and happen to explain an invention, we can understand design as a process of enacting the social.

One advantage to such a view of design would, of course, be that the divide between the "subjective" and "objective" could be abandoned. Presently, the object is grasped in two different ways: either through its intrinsic materiality (something that would define it as material, real, objective and factual) or through its more aesthetic or "symbolic" aspects (that would define an artifact as social, symbolic, subjective and lived). ANT helps us escape this modernist division. Suggesting that matter is absorbed into meaning, that design is in the world as the ANT terms script and prescription imply it, design studies could engage in analysis of how materiality from one side, and morality, ethics, politics from the other, are to coalesce in design.

By using this approach, we could do justice to the many material dimensions of things (without limiting them in advance to pure material properties or to social symbols). Matter is much too multidimensional, much too active, complex, surprising and counterintuitive to be represented in stabilized design artifacts or technical design drawings and charts. ${ }^{12}$ A second advantage of an ANT view of design is that it offers us a fuller view of these dimensions. Design embraces a complex conglomerate of many surprising agencies that are rarely taken into account by design theory. Such accounts of design reveal to what extent designers are attached to nonhumans; they can hardy conceive a new object or environment without being assisted and amplified by many drawings, tools, models and other devices. And that is what makes them so materially interesting.

I use the term design object, which might sound restrictive. ${ }^{13}$ Going back to my morning trajectory, I might recall a situation in which, due to an accident, the door lock refuses to work. Many of my colleagues, the Help Desk at the university, engineers and technicians will gather around the door and try to decipher the problem; technical reports will be written, and colleagues will complain that they can't access their mailboxes and stationery. This particular accident will trigger accountability on a larger scale: the door design 
and lock systems at the university will be assessed, university policy and disciplinary politics will be evaluated and discussed, etc. A simple object, the door lock, will become a "thing," a contested gathering of many conflicting demands; a disputed assemblage that will divide and congregate and will engage new assemblies of humans and nonhuman. ${ }^{14}$ Paradoxically, many design objects often appear as "things," not as mere objects; in design studies, a new design artifact is often a contested territory (Petroski 1993; Molotch 2005). These "things" cannot be reduced to a simple description of what they are and what they mean.

In this situation, we can witness how a thing or a design project can modify all the elements that try to contextualize it, triggering contextual mutations. In this sense, a design project or a disputed design thing resembles more a complex ecology than it does a static object. ${ }^{15}$ Instead of looking for explanations of design outside the design field, following an ANT perspective we should consider context as variable, that is as something moving, evolving and changing along with the various design objects themselves; context is made of the many dimensions that impinge at every stage on the development of a project. And that is the third advantage of an ANT perspective to design.

Instead of analyzing the impact of external factors (market forces, class divisions, economic constraints, social conventions, cultural climate, marketing games or politics) on design and particular design philosophies, we should attempt to grasp the erratic behavior of different types of matters in the experimental design venture. ANT gives us one more tool in which to follow the painstaking ways users react to and misuse the design objects and environments. Instead of referring to abstract theoretical frameworks outside design, ANT allows us a different way to study the negotiations of designers, producers, marketers and users. Only by generating such accounts of design processes and practices, tracing pluralities of concrete entities in the specific spaces and times of their co-existence, will design studies be able to contribute to our understanding of the social.

\section{Notes}

1. The term "script," borrowed from the sociology of technology, designates at the same time the vision of the world incorporated in the object and the program of action it is supposed to accomplish. To quote Madeleine Akrich, "By defining the characteristics of his object, the conceiver [in our case, the designer] puts forward a number of hypotheses concerning the elements making up the world into which the object is intended to fit. He proposes a 'script', a 'scenario', intended as a predetermination of the settings which users are called upon to imagine starting from the technical device and its accompanying prescriptions" (Akrich 1987; English version Akrich 1992). 
2. Drawing on the ecological approach, I use the term "affordance" as simultaneously referring to the object and to the environment and the observer. Neither objective nor subjective property, affordance is at the same time matter and mind, physical and phenomenal, and it points to the impossibility of separating the cultural environment from the natural one (Gibson 1979). Action is viewed as the realization of affordances and is intimately related to perception (Greeno 1994). In his later works on the psychology of everyday things, Norman (1988) shifts the focus of his analysis from the concept of affordance to the one of perceived affordance: "the designer cares more about what actions the user perceives to be possible than what is true" (Norman 1999: 38-9). Affordances specify the range of possible activities, but they should be visible to the users and, therefore, perceived. Hence, the art of the designer, argues Norman, is to ensure that the desired, relevant actions are readily perceivable. Other revisions of Gibson also focused on the role of intention in the Gibsonian view of visual perception and extended the meaning of the term affordance to include the culturally dependent functional significance of an object to an observer (Heft 1989).

3. The term "mediator" points to the fact that objects are participants in the course of action that is overtaken by other agencies, this being a main postulate of ANT (Latour 2005). If an intermediary is a black box that transports meaning without transformation, a mediator can transform, translate, distort and modify meaning; it is unpredictable and cannot serve as a reification of the social like many faithful and predictable intermediaries do (Latour 2005: 37-42).

4. To "delegate" action to nonhumans means that engineers and designers substitute design objects, environments and devices for the action of people and make them permanently occupy the position of humans so as to be able to shape human action by redistributing competences and prescribing responsibilities. The behavior imposed back onto the human by nonhuman delegates is termed prescription (Latour 1991). For instance, urban artifacts and environments are seen as authorizing and interdicting, giving permission or holding promises; instead of serving as passive and indifferent frames of subjective passions they are part of the complex webs that in turn make us part of a city and retain us in their flexible networks. With their specific design they make the user of the urban space blind but connected, partially intelligent, provisionally competent (Latour 1998: 90-105). Hidden policemen, fences, bicycle shades, fountains, barriers, etc, all these "objects have two faces: they multiply the possibilities of existences for those they shape; they multiply the possibilities to be absent for those they replace. Anthropogenic on one side, they are sociogenic on the other" (Latour 1998: 107). 
5. The term "nonhuman" is used by Bruno Latour to replace "object" and to broaden its scope. It is a "concept that has meaning only in the difference between the pair 'human-nonhuman' and the subject-object dichotomy [and] is not a way to 'overcome' the subject-object distinction, but a way to bypass it entirely" (Latour 1999: 308). His view is that nonhumans have an active role that is often forgotten or denied and he employs these two terms - human and nonhuman - to avoid the restricted roles for subjects and objects that suggest that objects are passive things for human subjects to use (Latour 1999: 303).

6. Social does not stand here for a synonym of "society," the latter being often understood as the hidden source of causality which could account for the existence and stability of different types of action or behavior (Latour 1991: 113), but as a way to connect heterogeneous actors and environments; it is to be composed, made up, constructed, established, maintained and assembled (Latour: 2005).

7. As he has put it: "we should shift from the study of 'social' factors to the study of 'associations'" (ibid.).

8. See the analysis by Latour of the Berlin key with two symmetrical bits, the so-called Schließzwangschlüssel (Latour 2000).

9. The debate surrounding the choice of the form of the assembly chambers at the time of the French Revolution shows how design facilitated a specific repertoire of actions and had a different impact on parliamentary behavior (Heurtin 1999).

10. On repetition as generating the social, see Tarde (1895). For an exploration of the infinitely mutable process of art and design, and numerous small repetitions of design moves deployed in uncertain situations of planning and designing, see Yaneva (2001, 2003). This approach allows objects to be defined not only by their components (material or symbolic) but also by the peculiar ways they are opened and closed, proliferated and black-boxed, multiplied and rarefied.

11. For a recent example of how ANT can be applied to architectural design, see Yaneva (2009).

12. For an ANT study of the practices of designers and the role that objects play in them, see Dubuisson and Hennion, 1995.

13. The examples discussed in this article concern mainly artifact design, but design should be tackled in a broader sense of the design of environments, cities, processes, cultures, atmospheres (Sloterdijk 2005). ANT has done very little in this direction; some exceptions are the studies on architectural design (Yaneva 2005, 2008; Houdart 2008).

14. On the notion of "thing" versus "object" see Latour and Weibel (2005).

15. See the web platform www.mappingcontroversies.co.uk 


\section{References}

Akrich, Madeleine. 1987. "Comment décrire les objets techniques?" Technique et culture, 9: 49-64.

Akrich, Madeleine. 1989. "La construction d'un système sociotechnique. Esquisse pour une anthropologie des techniques." Anthropologie et Sociétés, 13(2): 31-54.

Akrich, Madeleine. 1991. "L'analyse socio-technique." In Dominique Vinck (ed.), La gestion de la recherche. Brussels: De Boeck.

Akrich, Madeleine. 1992. "The De-scription of Technical Objects." In W. Bijker and J. Law (eds), Shaping Technology/Building Society: Studies in Sociotechnical Change. Cambridge, MA: MIT Press.

Akrich, Madeleine and Latour, Bruno. 1992. "A Summary of a Convenient Vocabulary for the Semiotics of Human and Nonhuman Assemblies." In W. Bijker and J. Law (eds), Shaping Technology/Building Society: Studies in Sociotechnical Change. Cambridge, MA: MIT Press.

Dubuisson, Sophie and Hennion, Antoine. 1995. "Le design industriel, entre création, technique et marché." Sociologie de l'art, 8: 9-30.

Evans, Robin. 1997. Translations From Drawing to Building. Cambridge, MA: MIT Press.

Gibson, James. 1979. The Ecological Approach to Visual Perception. Hillsdale, NJ and London: Lawrence Erlbaum Associates.

Greeno, James. 1994. "Gibson's Affordances." Psychological Review, 101(2): 336-42.

Heft, Harry. 1989. "Affordances and the Body: An Intentional Analysis of Gibson's Ecological Approach to Visual Perception." Journal for the Theory of Social Behaviour, 19: 1-30.

Heurtin, Jean-Philippe. 1999. L'espace publique parlamentaire. Essai sur les raisons du législateur. Paris: Presses Universitaires de France/P.U.F.

Hirschauer, Stephan. 2005. "On Doing Being a Stranger: The Practical Constitution of Civil Inattention." Journal for the Theory of Social Behaviour, 35(1): 41-67.

Houdart, Sophie. 2008. "Copying, Cutting and Pasting Social Spheres: Computer Designers' Participation in Architectural Projects." Science Studies, 21(1): 47-63.

Latour, Bruno. 1991. Nous n’avons jamais été modernes: essai d'anthropologie symétrique. Paris: La Découverte.

Latour, Bruno. 1996. "On Interobjectivity." Mind, Culture and Activity, 3: $228-45$.

Latour, Bruno. 1998. Paris, Ville Invisible. Paris: Les Empêcheurs de Penser en Rond/La Découverte.

Latour, Bruno. 1999. Pandora's Hope: an Essay on the Reality of Science Studies. Cambridge, MA and London: Harvard University Press. 
Latour, Bruno. 2000. "The Berlin Key or How to Do Things with Words." In Paul Graves-Brown (ed.), Matter, Materiality and Modern Culture. London: Routledge.

Latour, Bruno. 2005. Reassembling the Social: an Introduction to Actor-Network-Theory. Oxford: Oxford University Press.

Latour, Bruno and Weibel, Peter. 2005. Making Things Public. Cambridge, MA: MIT Press.

Molotch, Harvey. 2005. Where Stuff Comes From: How Toasters, Toilets, Cars, Computers and Many Other Things Come to Be As They Are. London: Routledge.

Norman, Donald. 1988. The Psychology of Everyday Things. New York: Basic Books.

Norman, Donald. 1999. "Affordance, Conventions and Design." Interactions, 5: 38-43.

Petroski, Henry. 1993. The Evolution of Useful Things. New York: Knopf.

Sloterdijk, Peter. 2005. Ecumes: Sphères III, Sphérologie plurielle. Paris: Maren Sell Editeurs.

Tarde, Gabriel. 1895. "Les deux éléments de la sociologie." In Etudes de psychologie sociale. Paris: Giard et Brière.

Yaneva, Albena. 2001. “L'affluence des objets: pragmatique comparée de l'art contemporain et de l'artisanat d'art." Doctoral thesis, Ecole Nationale Supérieure des Mines de Paris.

Yaneva, Albena. 2003. "Chalk Steps on the Museum Floor: The 'Pulses' of Objects in Art Installation." Journal of Material Culture, 8: 169-88.

Yaneva, Albena. 2005. "Scaling Up and Down: Extraction Trials in Architectural Design." Social Studies of Science, 35(6): 867-94.

Yaneva, Albena. 2008. "How Buildings 'Surprise': the Renovation of the Alte Aula in Vienna." Science Studies: An International Journal of Science and Technology, 21(1): 8-29.

Yaneva, Albena. 2009. The Making of a Building: A Pragmatist Approach to Architecture. Oxford: Peter Lang Publishers.

Zaff, B.S. 1995. "Designing with Affordances in Mind." In J. Flach, P. Hancock, J. Caird and K.J. Vicente (eds), Global Perspectives on the Ecology of Human-machine Systems. Hillsdale, NJ: Lawrence Erlbaum Associates. 